\title{
Representatives of Lepidoptera groups occurred in forestry and agricultural crops and their effective entomophage types
}

\author{
Rasul Jumaev ${ }^{1, *}$, Abdumannon Gazibekov ${ }^{1}$, Otabek Sulaymonov ${ }^{2}$, and Bekzod Sobirov ${ }^{2}$ \\ ${ }^{1}$ Tashkent State Agrarian University, University str., 2, Tashkent province, Uzbekistan, 100140 \\ ${ }^{2}$ Scientific Research Center for Plant Quarantine, Bobur str., 17, Tashkent, Uzbekistan
}

\begin{abstract}
This article summarizes the data collected on the basis of several years of scientific and practical research, and identifies the bioecology of the main Lepidoptera family with high rates of economic damage to forest and agricultural crops, developmental stages, and species composition and systematics. Accordingly, several species of parasitic entomophages belonging to the families Trichogrammatidae, Braconidae, Ichneumonidae, Chalcididae, Pteromalidae were studied and systematically analyzed for species composition.
\end{abstract}

\section{Introduction}

The drastic changes in the world's ecology and environment, the rapid application of innovative technologies by man to nature, are leading to the complete extinction of the biocenosis creatures that are unique to that place [1]. This poses a serious threat not only to agricultural crops but also to forests. The forest is leading to the disruption of the biodiversity balance in the biocenosis, environmental pollution, and a sharp increase in some pests. As a result, "the negative impact of pests on world agriculture is estimated at \$ 1.4 trillion, accounting for 5\% of global GDP" [2, 3-5] The conservation of biodiversity, the improvement of the system of biological control of pests is one of the pressing issues. Scientists around the world are conducting large-scale scientific research on many international fundamental, practical and innovative projects aimed at preserving forestry and agricultural products lost due to pests [1, 6-10].

Pests belonging to the main representatives of the Lepidoptera family were identified based on the damage they cause to agricultural crops. In particular, members of the family Lepidoptera, nightingales, moths, moths are the most widespread in the world $[11,12]$.

Only members of the Noctuidae family are included in the species of autumn and wild nightshades, which cause serious damage to vegetable crops [5, 12]. In addition, scientists have studied the corn stalk moth (Ostrinia nubilalis Hb.) which belongs to the family of moths. According to them, since this pest is omnivorous, it has been corrected to cause severe damage to crops such as corn, hemp, sesame, coarse hemp [13].

\footnotetext{
* Corresponding author: rasul-jumaev@,mail.ru
} 
In addition to the thousands of species of pests that cause major damage in the forest biocenosis, according to their research in the world's forests, more than 50,000 parasitic species of entomophagous pests in the forest, mainly Trichogrammatidae, Scelionidae Ichneumonidae, Chalidae, Braconidae, Braconidae eaten and they damage the imago, eggs, worms and fungi of forest pests [14].

Considering all the above, the purpose of the study is determine the bioecology of the main representatives of the genus Lepidoptera, which cause great damage to forest and agricultural crops, and their species composition. It also takes into account the parasitic entomophagous species of these pests, observes the formation of their balance between the pest and the parasite, and their systematic analysis. The importance of biological control in managing the number of pests in the biocenosis is infinite, and we aimed to study the fauna of entomophagous species belonging to the family Hymnoptera in managing the number of key representatives of the family Lepidoptera.

\section{Materials and methods}

During the research, entomological handles, special nets, various artificially prepared yeasts were used to collect pest imagos. Different stages of development of the Lepidoptera family collected from the biocenosis were collected and observed in several types in special containers.

The main representatives of the genus Lepidoptera, found in forest and agricultural agrobiocenosis, collected 720 butterflies, 65 eggs, 6800 worms of different ages, 71 fungi. During the experiment from the following microscopes: MBS-2; MBI-3; electron microscope Telsa-BS-613 (Czech); thermostat MEMMERT E05273 and other appliances were used $[15,16]$.

\section{Results and discussion}

Scientific research has been conducted in various biocenoses and on the local insect fauna. The main representatives of the genus Lepidoptera occurring in the forest biocenosis were determined. Preliminary observations were made on the species composition of pests belonging to the genus Lepidoptera, in which insects in the forest biocenosis were captured using special traps (Table 1).

Table 1. Main representatives of the genus Lepidoptera found in the forest biocenosis (Burchmulla forestry of Tashkent province 2018-2019. Credits: A. Gozibekov)

\begin{tabular}{|c|c|c|c|}
\hline$\#$ & Latin name of the pest & English name of the pest & \multirow{2}{*|}{ Damage rate } \\
\hline \multicolumn{5}{|c|}{ Eribidae family } \\
\hline $\mathbf{1}$ & Lymantria dispar $L$. & Gypsy moth & +++ \\
\hline \multicolumn{5}{|c|}{ Tortricidae family } \\
\hline 1 & Tmetocera ocellana $F$. & Bud moth & ++ \\
\hline 2 & Recarvaria nanella Schiff & Lesser bud moth & + \\
\hline 3 & Carpocapsa pomonella $L$ & Codling moth & +++ \\
\hline
\end{tabular}




\begin{tabular}{|c|c|c|c|}
\hline 4 & Grapholitha molesta & Fruit moth & ++ \\
\hline \multicolumn{3}{|c|}{ Plutellidae family } \\
\hline 1 & Yponomeuta malinellus Zell. & Apple ermine moth & ++ \\
\hline 2 & Coleophora hemerobiola Fil & Fruit tree case moth & + \\
\hline 3 & Cemiostoma scitella Zell & Leaf blister moth & ++ \\
\hline \multicolumn{4}{|c|}{ Pieridae family } \\
\hline 1 & Aporia crataegi L. & Black-veined white butterfly & ++ \\
\hline 2 & Cyaniris argiolus $L$. & Holly blue butterfly & +++ \\
\hline 3 & Zeuzera pyrina & Leopard moth & ++ \\
\hline \multicolumn{5}{|c|}{ Cymbidae family } \\
\hline 1 & $\begin{array}{c}\text { Sarrothripus musculana } \\
\text { Ersch }\end{array}$ & Asian walnut moth & +++ \\
\hline
\end{tabular}

Note: The degree of damage is $(+++)$ high, $(++)$ average, and (+) low.

In the forest biocenosis, our research to identify the main representatives of the Lepidoptera family has yielded results. 5 species of Lepidoptera were found in the garden biocenosis.

Studies have identified pest species that can cause significant economic damage to the apple tree. In the agrobiocenosis, the parasite-entomophagous relationships of the Lepidoptera family play an important role in maintaining the rhythm of the parasite-host relationship. As a result of abrupt changes in environmental factors, the balance between them is disturbed, leading to a mass increase of the host. Subsequent studies revealed 5 species of Noctuidae of Lepidoptera family and 2 main species of Pyralidae in Buka, Bekabad, Orta Chirchik and Yukori Chirchik districts of Tashkent province (Figure 1 and Table 2).
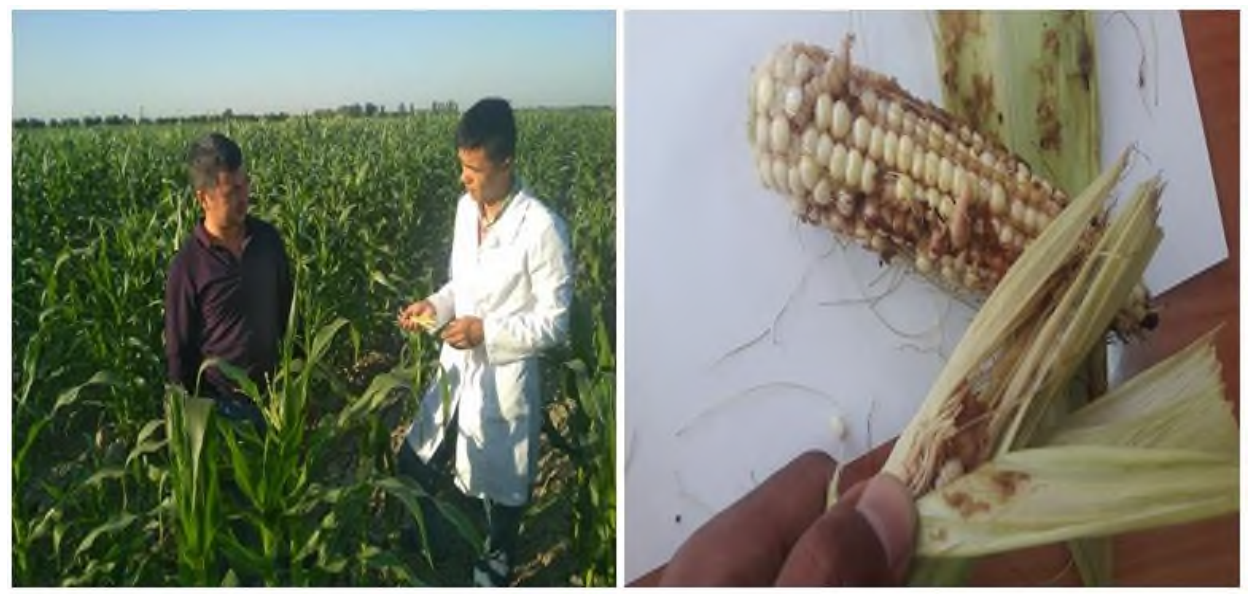

Fig.1. Infection of corn with the pest Ostrinia nubilalis Hb. (Tashkent province, 2019) 
Table 2. Representatives of the main families and species of the genus Lepidoptera found in the corn agrobiocenosis of Tashkent province (2016-2019)

\begin{tabular}{|c|c|c|c|}
\hline \# & Latin name of the pest & English name of the pest & Damage rate \\
\hline \multicolumn{5}{|c|}{ Noctuidae family } \\
\hline 1 & Helicoverpa armigera $\mathrm{Hbn}$ & Cotton bollworm & +++ \\
\hline 2 & Agrotis rotis segetum Den & Turnip moth & +++ \\
\hline 3 & Mythimna vitellina $\mathrm{Hb}$. & Aletia & +++ \\
\hline 4 & Agrotis exclamationis $\mathrm{L}$ & Heart and dart moth & ++ \\
\hline 5 & Agrotis ipsilon Hufn & Black cutworm & + \\
\hline \multicolumn{5}{|c|}{ Pyralidae family } \\
\hline 1 & Ostrinia nubilalis $\mathrm{Hb}$ & Maize borer & +++ \\
\hline 2 & Ostrinia kasmirica Moore & European maize moth & ++ \\
\hline
\end{tabular}

Note: The degree of damage is (+++) high, $(++)$ average, and (+) low.

The main species of the Noctuidae family in maize are Helicoverpa armigera Hbn, Agrotis segetum Den et Schiff, and Mythimna vitellina Hb. The most common and relatively rare species were Agrotis exclamationis, and Agrotis ipsilon Hufn species. However, with a population density of these dominant species, Agrotis segetum Den et (10.2\%), Helicoverpa armigera Hbn, and Mythimna vitellina $\mathrm{Hb}$. (54.1\%) species were distinguished.

Representatives of the Pyralidae family, the main 2 species Ostrinia nubilalis $\mathrm{Hb}$ and Ostrinia kasmirica Moore, were found to cause serious damage to $65-70 \%$ of the yield of corn due to the growing season (Table 3).

Table 3. Parasitic entomophagous species of the genus Hymenoptera of the genus Lepidoptera occurring in forest and maize agrobiocenoses

\begin{tabular}{|c|c|c|c|}
\hline$\#$ & Types of parasites & Pest type & Nutrition sources \\
\hline $\mathbf{1}$ & Trichogrammatidae family & Tiny wasp pests & Larvae \\
\hline 1.1 & $\begin{array}{c}\text { Trichogramma ostriniae Hb } \\
\text { Trichogramma dendrolimi }\end{array}$ & $-/ /-$ & $-/ /-$ \\
\hline $\mathbf{2}$ & Braconidae family & Tiny wasps & $\begin{array}{c}\text { Own mature worms, } \\
\text { beetles }\end{array}$ \\
\hline 2.1 & Therion circumflexum $\mathrm{L}$ & $-/ /-$ & $-/ /-$ \\
\hline 2.2 & Apanteles telengai Tobias & $-/ /-$ & $-/ /-$ \\
\hline 2.3 & Bracon hebetor Say & $-/ /-$ & $-/ /-$ \\
\hline 2.4 & Cotesia melanoscela & $-/ /-$ & $-/ /-$ \\
\hline 2.8 & Microctonus aethiopoides & $-/ /-$ & $-/ /-$ \\
\hline $\mathbf{3}$ & Ichneumonidae family & $-/ /-$ & $-/ /-$ \\
\hline 3.1 & Pimpla turionellae & $-/ /-$ & $-/ /-$ \\
\hline 3.2 & Pimpla instigator & $-/ /-$ & $-/ /-$ \\
\hline 3.3 & Apechtis compunctor & $-/ /-$ & $-/ /-$ \\
\hline 3.4 & Apechtis capulifera & $-/ /-$ & \\
\hline
\end{tabular}




\begin{tabular}{|c|c|c|c|}
\hline 3.5 & Theronia atalantae & $-/ /-$ & $-/ /-$ \\
\hline 3.6 & Stilpnus tenuipes & $-/ /-$ & $-/ /-$ \\
\hline 3.7 & Lymantrichneumon disparis & $-/ /-$ & $-/ /-$ \\
\hline $\mathbf{4}$ & Chalcididae family & Chalcidid moths & Own worms, larvae \\
\hline 4.1 & Brachymeria intermedia & $-/ /-$ & $-/ /-$ \\
\hline 4.2 & Rhaphitelus maculates Wlk & $-/ /-$ & $-/ /-$ \\
\hline $\mathbf{5}$ & Eupelmidae family & Chalcidid moths & Own worms, larvae \\
\hline 5.1 & Anastatus japonicus & $-/ /-$ & $-/ /-$ \\
\hline
\end{tabular}

Observations were made on corn fields over the years, and the occurrence of the above pests was summarized and averaged. Specialized parasite of this pest Trichogramma ostriniae $\mathrm{Hb}$ type is propagated by Tashkent State Agrarian University and Scientific Research Center for Biological Protection of Plants (Figure 2).
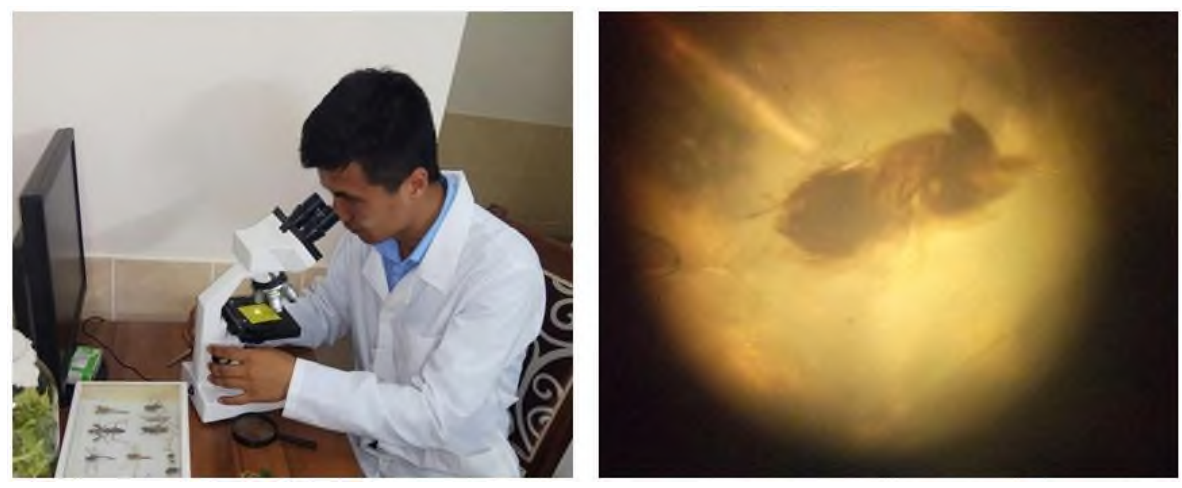

Fig. 2. Reproduction of new species of trichogramma in biolaboratory

According to the results of scientific research conducted in 2010-2020, a variety of parasites and predatory entomophagous species were observed in the biocenosis of the country, and $66.4 \%$ of the total entomophagous composition was parasites. In the biocenosis, the parasite-host relationship of the Lepidoptera family is ensured to be continuous. Because if they have a parasite or host-relationship relationship, the population of a species can increase dramatically or become extinct altogether.

The main entomophagous species that effectively control the number of representatives of the family Lepidoptera are found in the family Trichogrammatidae, Braconidae, Ichneumonidae, Chalcididae and, Eupelmidae. (Figure 3). 

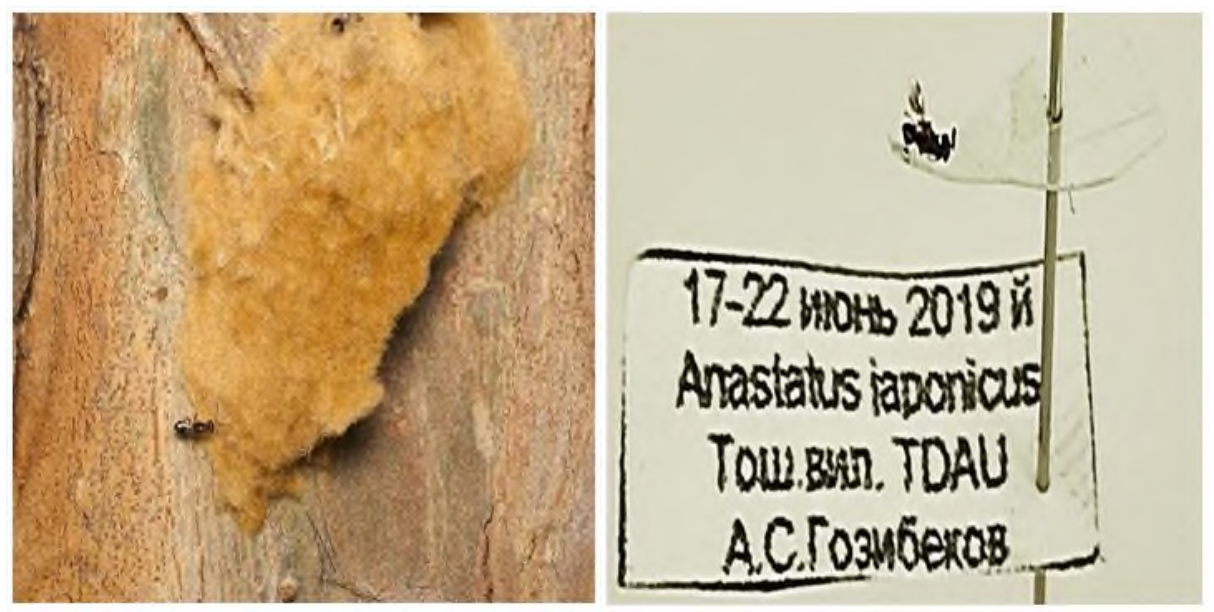

Fig. 3. Anastatus japonicus parasite entomophagous type (Tashkent province, 2019)

Among the representatives of this parasitic entomophagous family are effective parasitic entomophagous of leafhoppers and cocoons. Anastatus japonicus belonging to the family Eupelmidae and Brachymeria intermedia belonging to the family Chalcididae have been identified and these species have not been thoroughly analyzed by scientists of our country $[6 ; 7 ; 8 ; 9]$.

Based on the data provided in the literature of these three species of world scientists, as well as in the laboratory, the composition of the species was determined. There are many species of parasitic entomophages in the biocenosis of our country, which are still not fully understood. They are important in controlling the number of pests (Figure 4).
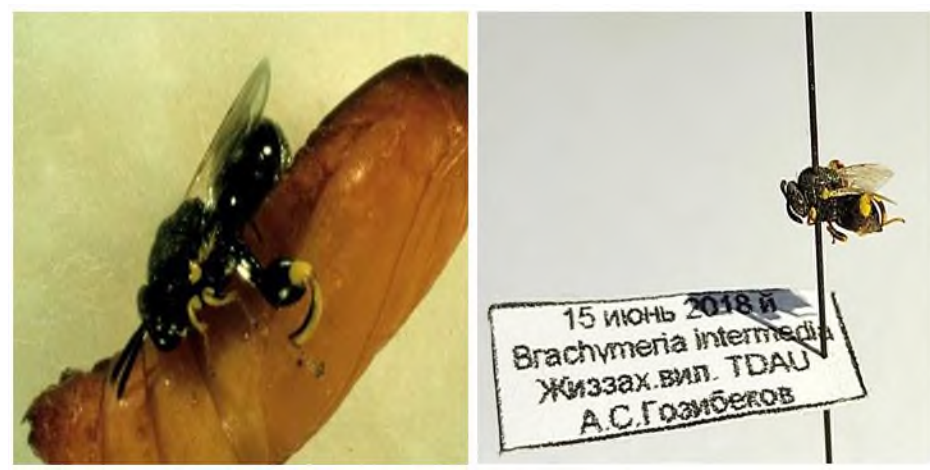

Fig. 4. Brachymeria intermedia parasite entomophagous type (Jizzakh province, 2019-2020)

There are 90 species of entomophagous parasites belonging to the family Chalcididae, known to us from the literature of world scientists. Not all of these species play an important role in managing the number of pests.

However, our research has shown that Brachymeria intermedia parasite entomophagy, another species that has not been previously recorded in our forest biocenosis and has not been studied in depth by our scientists, plays an important role in the effective management of an unequal number of silkworms. In the study, we brought this species to the biolaboratory in the fungi of unequal silkworms in the biocenosis of the State Forest Reserve of Zaamin district of Jizzakh province, and as a result of systematic analysis, we 
identified this species as Brachymeria intermedia. This species was identified in 1864 by Professor Nees (Table 4).

Table 4. Leading parasite-entomophagous species of the Hymenoptera family in the biocenosis and their ratio and level of occurrence

\begin{tabular}{|c|c|c|c|c|}
\hline$\#$ & Types of parasites & Detected leader type & $\begin{array}{c}\text { Parasite/leader } \\
\text { ratio }\end{array}$ & $\begin{array}{c}\text { Incidence rate of } \\
\text { parasite species }\end{array}$ \\
\hline 1 & $\begin{array}{c}\text { Apanteles telengai } \\
\text { Tobias }\end{array}$ & Ostrinia nubilalis $\mathrm{Hb}$ & $1: 12$ & +++ \\
\hline 2 & $\begin{array}{c}\text { Microgaster } \\
\text { mediator } \mathrm{Hal}\end{array}$ & Ostrinia kasmirica Moore & $1: 43$ & ++ \\
\hline 3 & Bracon radialis Tel & Syngrapha circumflexa L. & $1: 36$ & ++ \\
\hline 4 & $\begin{array}{c}\text { Rogas dimidiatus } \\
\text { Spin }\end{array}$ & Agrotis exclamationis L. & $1: 44$ & ++ \\
\hline 5 & $\begin{array}{c}\text { Brachymeria } \\
\text { intermedia }\end{array}$ & Lymantria dispar $\mathrm{L}$ & $1: 18$ & + \\
\hline
\end{tabular}

Note: The degree of incidence is (+++) high, (++) average, (+) low.

Of course, in the biocenosis, it was observed that agricultural crops multiply rapidly and cause more damage due to the favorable conditions for the survival of the main pests. In order to reduce their numbers harmlessly, it will be necessary to create agrotechnical methods and a comfortable indoor environment that attracts their parasites and predators.

\section{Conclusion}

According to the results of many years (2010-2020) studies, we can say that the representatives of the Hymenoptera family are effective parasitic entomophagous in controlling the number of representatives of the Lepidoptera family.

The study revealed that 16 species of Noctuidae family were registered in the agrocenosis of Tashkent province, and 12 species of Vraconidae family were found in the management of the number of these species. This means that a large part of the number of nightingales can be effectively managed by members of the poaching family.

In forest and corn agrobiocenoses more than 100 species of the family Trichogrammatidae, Braconidae, Ichneumonidae, Chalcididae, which are effective entomophagous representatives of the family Lepidoptera, were observed. Trichogramma evanescens Westv Trichogramma pintoi Voeg Trichogramma ostriniae Hb of the family Trichogrammatidae, which is a new species for the entomofauna of Uzbekistan, and species Anastatus japonicus belonging to the family Eupelmidae and a species belonging to the family Chalcididae $B$.

\section{References}

1. A. Anorbaev, O. Sulaymonov, R. Jumaev, A. Gozibekov, B. Sobirov, Agro-knowledge 1(57), 39-41 (2019)

2. A. Anorbaev, B. Sulaymonov, KH. Kimsanbaev, Bulletin of Agrarian Sciences 3(57), 33-36 (2014)

3. T. V. Varina, Niva Kubani 42, 22-23 (2002) 
4. R. Jumaev, K. Kimsanbaev, S. Ubaydullaev, J. Abdurakhmanova, Actual Problems of Modern Science 2(99), 95-101 (2018)

5. R. Jumaev, S. Sabirov, N. Juraeva, European Science Review 3-4, 25-28 (2018)

6. O. Sulaymonov, A. Anorbaev, R. Jumaev, B. Sobirov, American Journal of Agri. And Bio Eng, 153-158 (2020)

7. O. Sulaymonov, A. Anorbaev, R. Jumaev, B. Sobirov, Actual Problems of Modern Science 5(114), 151-156 (2020)

8. O. Sulaymonov, B. Sobirov, Proceedings of International Multidisciplinary Scientific Conference on Innovative Technology, 156-160 (2020)

9. R. Jumaev, B. Sobirov, M. Tadjieva, Bulletin of Agrarian Sciences 1(71), 68-70 (2018)

10. E. Cuevas-Mendieta, E. García-Frapolli, E. del-Val, Forest Ecology and Management 482, 118815 (2021)

11. J. A. Ugwu, M. Liu, H. Sun, F. O. Asiegbu, Journal of Applied Entomology 144(9), 764-776 (2020)

12. B. Sulaymonov, R. Jumaev, B. Sobirov, A. Gozibekov, Bulletin of Agrarian Sciences 1(71), 70-73 (2018)

13. J. W. Evans, Coun Sci Ind Res 3(2), 106-116 (2010)

14. S. Firempong, M. P. Zalucki, Australian Journal of Zoology 37, 665-673 (1990)

15. M. Jallow, M. Zalucki, Australian Journal of Zoology 44, 503-519 (1996)

16. H. G. Marco, P. Šimek, G. Gäde, Frontiers in physiology, 11 (2020) 